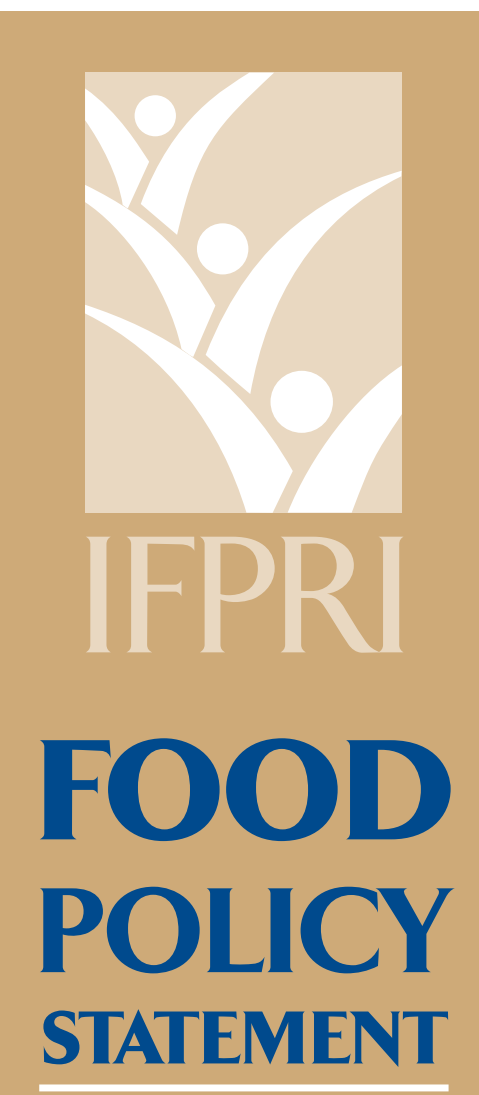

NUMBER 43, JULY 2006

INTERNATIONAL

FOOD POLICY

RESEARCH

INSTITUTE

2033 K STREET, N.W.

WASHINGTON, D.C. 20006-1002

U.S.A.

PHONE: +1-202-862-5600

FAX: +1-202-467-4439

EMAIL: IFPRI@CGIAR.ORG

WEB: WWWIIFPRI.ORG

\section{AIDS, POVERTY, AND HUNGER CHALLENGES AND RESPONSES}

\section{STUART GILLESPIE}

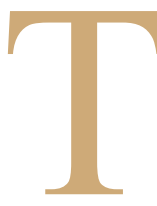

he global AIDS epidemic has caused more than 25 million deaths since 1981, and there is no end in sight. It is a multidimensional, phased, long-wave crisis with impacts that will be felt for decades to come. The first phase involves HIV infection itself, followed by an increasing incidence of opportunistic infections such as tuberculosis and, several years later, by AIDS illness and death. The fourth and final phase-depending on the prevalence of the disease and the availability of treatment and other mitigation measures - involves an accumulation of macroeconomic and social impacts at household, community, and national levels.

While a few countries have brought down infection rates, no country has yet seen a downturn in AIDS mortality, and the fourth phase is only just beginning for most of the affected regions. These multidimensional, long-wave characteristics, combined with the fact that AIDS disproportionately strikes the most productive members of society, are what sets HIV and AIDS apart from many other health shocks.

\section{INTERNATIONAL CONFERENCE: FROM EVIDENCE TO ACTION}

gainst this backdrop, the International Food Policy Research Institute (IFPRI) held a

conference in South Africa in 2005 to bring together researchers and practitioners to review the existing evidence and its implications for future food- and nutrition-relevant policy, and to highlight remaining knowledge gaps. It also aimed to forge links among countries, sectors, and perspectives in both research and action. Fifty papers selected by an external review panel were presented. Eighteen of them, written by international experts in agricultural economics, health, anthropology, and nutrition, make up AIDS, Poverty, and Hunger: Challenges and Responses.

The essays revolve around three key issues and questions:

- Interactions. What is known about the interactions between agriculture and other rural livelihood systems, the spread of HIV, and the impacts of AIDS at different levels?

- Local responses. What is known about the capacities and strategies of households and communities to reduce the risk of infection (resistance) and to respond effectively to the impacts of HIV and AIDS (resilience)? What do these strategies imply for the types of support needed from governments, civil society, the private sector, and international agencies?

- Policies, programs, interventions. What is known about the processes and impacts of food- and nutrition-relevant policies, programs, and interventions that have been implemented to prevent the spread of HIV and/or mitigate the impacts of AIDS?

In particular, the authors examine the impacts of HIV and AIDS on labor markets and wages, household income and consumption dynamics, and on the agricultural sector as a whole; analyze the ways in which households respond to prime-age illness, death, and food insecurity; and study the implications of such local responses for the roles of national and international actors in addressing the AIDS-hunger nexus. 
Many of the contributors found it useful to focus on household, community, and institutional interactions by using a livelihoods framework to show how HIV and AIDS affect, and are affected by, people's livelihoods in an iterative cycle. According to this framework, the pathway that HIV takes through households and communities is as follows: first, various macro-level factors and conditions (such as historical, economic, cultural, political, and climatic) help determine both the susceptibility and vulnerability of different livelihood systems to HIV and AIDS. People's risk of contracting HIV, in turn, partly depends on the susceptibility of the livelihood system on which they depend, while the downstream effects of the disease on assets and institutions will be conditioned by the vulnerability of the system. After HIV has entered a household or community, the type and severity of its impact will to some extent determine the differing types of strategies that the household adopts. Such strategies then lead to various outcomes, including levels of nutrition and food security, which will themselves condition future susceptibility and vulnerability of the livelihood systems.

\section{IMPLICATIONS FOR POLICY}

T IV is exposing the fragility of 1 - people's livelihoods in hard-hit countries - a fragility that derives from multiple sources of vulnerability, many of which interact with and are worsened by AIDS, including food insecurity and malnutrition. Attempts to defeat the epidemic are conventionally grounded in the three core pillars of AIDS policy: prevention, treatment and care, and mitigation. But there is also an urgent need for a deeper understanding of the integral role that food and nutrition can and should play in all three strategies, and a corresponding urgency to use that understanding to improve responses at all levels.

It is especially important to identify which community-driven responses are working before looking at ways to provide support where local response capacity is exceeded. This in turn requires a clear articulation of the roles of other stakeholders, including the state, in a broad-based system of social protection.

Multisectoral involvement is also required. Decisionmakers must acknowledge AIDS as a development issue and then critically review existing programs and policies through the lens of their growing knowledge of AIDS interactions. It is a process that must involve continual reflection and the progressive development and application of responses, as opposed to predesigned interventions.

This increased awareness will allow food, nutrition, and development professionals to develop the conceptual links lacking in current multisectoral frameworks, assess impacts and costs, propose indicators and monitoring systems, and design appropriate food- and nutritionrelated interventions and policies.

Copyright @ 2006 International Food Policy Research Institute. All rights reserved.

INTERNATIONAL FOOD POLICY RESEARCH INSTITUTE • $2033 \mathrm{~K}$ STREET, NW •WASHINGTON, DC $20006-$ I002 USA

T: + I-202-862-5600•F: + I-202-467-4439• ifpri@cgiar.org・www.ifpri.org

IFPRI is supported by the Consultative Group on International Agricultural Research (CGIAR).

\section{Order online: http://www.ifpri.org/pubs/pubs.htm\#books}

To order by post, please fill out and send this coupon to Publication Services at IFPRI.

Please note: A single copy is free; additional copies cost $\$ 20.00$ each plus postage (enclose check or money order made payable to the International Food Policy Research Institute in U.S. currency).

Please send me __ copy/ies of AIDS, Poverty, and Hunger: Challenges and Responses, edited by Stuart Gillespie. Paperback / ISBN 0-89629-758-6 / 2006 / \$20.00 / 376 pages / Order Code OC50

Name/Title

Organization

Address 